perimente des Hirnforschers Walter Rudolf Hess, dessen Werk 1949 mit dem Nobelpreis geehrt wurde, war das Medium ein technisches Mittel unter anderen, wenn auch ein wichtiges. Obwohl die Filmer der Fernsehreihe «MenschenTechnik-Wissenschaft» nach der Devise: «Labor ist langweilig» handeln, kombinieren auch sie die Technik mit der wissenschaftlich genauen Beobachtung. Die Kommentare zu ausgewählten Filmsequenzen des Biologen und Kameramanns Andreas Moser gehörten zum Besten der Vortragsreihe, auch wenn er sein Referat aus uner- findlichen Gründen auf Englisch hielt. In der Kategorie des Tierfilms ergänzen sich die verschiedenen Ansprüche von Film und Wissenschaft, von Kommerz und Belehrung. Originalaufnahmen in freier Wildbahn, versteckte Manipulationen, Authentisches und Gestelltes, geschönte Realität und menschliche Projektionen addieren sich zum Gesamtkunstwerk. Inzwischen haben die ungleichen Zwillinge jeden gesellschaftlichen Bereich erobert. Realität und Fiktion sind nicht mehr auseinanderzuhalten.

\title{
Zauberberg
}

\section{Enrico Danieli}

Korrespondenz:

Dr. med. Enrico Danieli

Via ai Colli 22

CH-6648 Minusio
Möglich, dass erst im nachhinein die Stimme, wiederholt hörte ich diese Szene aus dem Grammophon - «in diesem Augenblick geschieht das Eisenbahnunglück ... Es gab einen Stoss - aber mit Stoss ist wenig gesagt ... unbedingt bösartig, abscheulich: Halt! Halt! Halt!» - und die so oft als möglich gelesene Stelle aus dem «Anneli»-, «Meieli», las ich zum x-ten Mal, «mach doch die Augen auf!», doch dann begann Meieli so zu husten, dass man meinte, es ersticke» - zu einer gleichzeitigen Empfindung sich verdichteten: Zumindest hingen die rauhe Stimme des Erzählers mit dem erstickenden Husten im Buch zusammen, Unglück mit Blut, vereinigten sich zu einem Schreck, der über die Kinderzeit hinaus andauerte.

Grossvater, Fabrikant, gerühriger Patron einer Sägerei, Holzfachmann, Politiker, Grossvater soll viel zu jung in einem Sanatorium, wo er, früh am Morgen, um das Herdengeläut besser zu hören, am offenen Fenster steht, tot zusammengebrochen sein. Und von Vaters Bruder hiess es, er sei schwach auf der Brust gewesen, habe, hervorgerufen durch zu vieles Reisen, durch kulturelles und gesellschaftliches Engagement, als Folge des ungesunden Klimas der Tropen und noch viel mehr durch die kubanischen Zigarren, früh schon Blut gehustet und sei viel zu früh an einem Blutsturz gestorben. Doch Meielis Tod im Kinderbuch von Olga Meyer war der Tod, der mich betraf, nicht nur, weil mein Kinderschatz Meieli hiess, sondern weil hier ein Kind, ein gutes, ein braves, ein unschuldiges, ein Kind wie ich, an Husten, an Spucken, an Auszehrung, an innerer Hitze, am Bluthusten, am Blutspucken elendiglich stirbt.

Es waren diese frühen Tode, die mich verwirrten, verunsicherten. Der Tod als Endpunkt von Krankheit, der Tod als Endpunkt des Lebens. Und, wie ich nun wusste, selbst ein Kind war nicht mit Sicherheit vor dem Tod, dem frühen, dem ungerechten, dem bösen, wie ich ihn heimlich nannte, geschützt. Und doch ging vom Erlöser auch eine eigentümliche Faszination aus: Eine Sympathie mit dem Tod war mir nicht fremd, Krankheit und Tod erschienen mir von verlockender Schönheit: Die dunklen Geheimnisse des Lebens führten ja doch alle zu ihm. Jemanden kennen, weil man seine Stimme schon gehört hat, ist ein Ereignis: Es gab die 33-TourenSchallplatte mit dem «Eisenbahnunglück», die sich auf welch verschlungenen Wegen auch immer auf unserem Kindergrammophon verirrte, sich drehte und drehte, der wir stumm, eben totenstill, zuhörten: Dem Unglück, der Erzählerstimme des Unglücks. Wir, im Schneidersitz auf dem Boden sitzend, stellten uns den Erzähler, Passagier im Zug, immer wieder als Herrn vor: Ein grossgewachsener Mann im langen Mantel und mit Mappe, mit Hut, rauchend, vornehm, ein Mann, der mit uns Kindern sicher nicht gesprochen hätte. Aber dass nun alle diese Dinge, diese rauhe, ein wenig zögernd vorlesende Stimme, Meielis Blutsturztod, Grossvaters Sanatoriumstod, des Onkels kubanische Zigarren und Brustschwäche zusammengehörten, von 
unsichtbaren Fäden zusammengehalten wurden, hätte ich mir im Traum nicht vorstellen können, erfuhr ich auch erst viel später im Zbg.

Zum Zauberberg kam ich rein zufällig in der Mittelschule durch einen freigewordenen Platz im Freifach Deutsche Literatur, er versprach einen Ausgleich zu bilden zu den mathematischnaturwissenschaftlich dominierten Fächern dieser elitären Schule. Dass ich nun unvermittelt dem Mann vom Eisenbahnunglück gegenüberstand, nicht seiner Stimme, sondern seinen Sätzen, stürzte mich in einen neuen Abgrund: Höhensonne, Liegekuren, Inhalationen, Pneumothorax, Pleuraschock, Rippenresektionen auf der einen Seite, Thermometer, Blauer Heinrich, Stumme Schwester, Sauerstoff auf der anderen Seite, und ganz im Zentrum die Moribunden, der Tod: Gesichtsschwellung, Austrocknung des inneren Mundes, beim Sprechen Mümmeln wie ein ganz Alter, das Auge bricht, die unbewusste Anstrengung der Züge weicht, die Mühsalsschwellung der Lippen schwindet, Verschönerung zu frühmännlicher Jugendlichkeit breitet sich aus ... und so war's geschehen.
Krankheit: Hier also fand ich, was ich längst gesucht hatte, Krankheit als Ausdruck einer psychologischen, sozialen, politischen und kulturellen Krise, Krankheit und Tod als Beherrschung all meiner Gedanken. Und hier, bei und mit Thomas Mann, wurde ich fündig: Die Tuberkulosekrankheit im Zauberberg, die stillstehende Zeit, die tiefe Einsicht, dass alle Gesundheit durch die Erfahrungen von Krankheit und Tod hindurchgegangen sein muss. Auf diese Weise gelang es mir schliesslich, meine Sympathie mit dem Tode zu überwinden: Das Nichts war praktisch greifbar geworden, denn während des Essens holten sie die Toten. Zum Leben, heisst es, gibt es zwei Wege, der eine ist der gewöhnliche, direkte, brave. Der andere ist schlimm; er führt über den Tod, und das ist der geniale Weg. Der Zauberberg ohne Zweifel als ein nicht enden wollender Initiationsroman, letztlich als das Buch - von spottenden Kritikern als reines Anatomisches Präparat abgetan -, das den notwendigen Durchgang zum Wissen, zur Gesundheit und schliesslich zum Leben darstellte und noch immer darstellt. 